\title{
E-EXPERTDIET: SISTEMA DESKTOP DE RACIOCÍNIO BASEADO EM CASOS PARA ANÁLISE DE PLANO ALIMENTAR
}

\section{E-EXPERTDIET: DESKTOP SYSTEM OF CASE-BASED REASONING FOR FOOD PLAN ANALYSIS}

\section{Daniel Borba de Souza}

\section{Centro universitário UNIFACVEST, Lages/SC}

E-mail: daniel.borba.souza@hotmail.com

RESUMO - O e-ExpertDiet é um sistema baseado em caso, mais conhecido pela sigla $R B C$, desenvolvido na linguagem de programação $J a v a^{1}$ com a utilização de sua base de dados no sistema gerenciador de banco de dados $S Q L^{2}{ }^{2}$ afim de auxiliar o profissional de nutrição gerar um plano alimentar equilibrado e expor índices baseados nos dados de referências atualizados ou criados ao realizar a análise. No trabalho, são abordados os fatores que influenciam a alimentação, a importância dos profissionais de nutrição e de gerar plano alimentar, destacando as funcionalidades do sistema $R B C$ desenvolvido para facilitar a precisão desses cardápios montados.

Palavras-chave: Alimentação, Plano Alimentar, RBC.

Recebido em: 03/12/2018

Revisado em: 20/02/2019

Aprovado em: 04/06/2019

ABSTRACT - The e-ExpertDiet is an RBC system developed a Java programming language with the use of its database in the SQL database manager system to assist the professional in creating a balanced food plan and exporter for the reference databases close to tried the analysis. The job has the factors that influence the feeding, the potential of nutritive and an nutcrising plane feeding, destacated the system of RBC development for accelerated the assembled menus.

Keywords: Food, Food Plan, RBC.

\footnotetext{
${ }^{1}$ Java é uma linguagem de programação orientada a objeto, possibilitando a utilização de múltiplas plataformas.

${ }^{2}$ Linguagem de Consulta Estruturada ou SQL, é a linguagem de pesquisa declarativa padrão para banco de dados relacional. 


\section{INTRODUÇÃO}

A saúde está associada à maneira como as pessoas se alimentam diariamente e pode provocar resultados irreversíveis caso a dieta seja deficiente.

A saúde é uma tarefa que deve ser conquistada a cada minuto durante toda nossa existência e embora inúmeros fatores possam fortemente influenciá-la, ela depende essencialmente da maneira pela qual o indivíduo se alimenta. (TURANO; ALMEIDA, 1999 apud DARTORA et al., 2006, p. 201).

O trabalho do nutricionista tornou-se indispensável para os seres humanos. Dessa forma, surge a necessidade de novas ferramentas para automatizar as atividades desses profissionais. Um sistema $R B C$ que os auxilie na elaboração de um plano alimentar equilibrado, levando em consideração valores de referência às DRIs (Dietary Reference Intakes).

Para Fernandes (2003) um sistema baseado em casos, utiliza experiências sofridas no passado, compara com um problema do presente e gera a resolução. Partindo desse princípio, ocorreu o desenvolvimento do sistema desktop eExpertDiet, que auxilia na otimização do trabalho realizado pelos nutricionistas, possibilitando com isso, maior eficiência de tempo nas consultas e visibilidade do cardápio semanal montado para seus clientes.

O presente trabalho abordará uma breve introdução sobre a conceituação de sistema $R B C$, bem como apresentar alguns aspectos que influenciaram a alimentação, destacando principalmente um sistema desenvolvido em Java para fins acadêmicos que objetivam o auxílio de profissionais de nutrição, na criação de planos alimentares equilibrados e precisos.

\section{SISTEMAS DE RACIOCÍNIO BASEADO EM CASOS}

Para Fernandes (2003), sistemas $R B C$ são sistemas baseados no conhecimento humano usando um referencial teórico com regras que auxiliam na resolução de um problema do passado. Essas regras têm que estar bem organizadas na base de conhecimento para sua comparação ocorrer com facilidade.

As partes integrantes de um sistema baseado em caso estão expostas no quadro:

QUADRO 1. FORMAÇÃO DE UM SISTEMA BASEADO EM CASO

\begin{tabular}{|c|l|}
\hline Estruturas & \multicolumn{1}{|c|}{ Conceituações } \\
\hline $\begin{array}{c}\text { Representação } \\
\text { do }\end{array}$ & $\begin{array}{l}\text { A representação da base de } \\
\text { conhecimento } \\
\text { forma de casos pré- } \\
\text { definidos. }\end{array}$ \\
\hline $\begin{array}{c}\text { Medida de } \\
\text { Similaridade }\end{array}$ & $\begin{array}{l}\text { Mecanismos que operam } \\
\text { para buscar associações } \\
\text { com os casos já existentes. }\end{array}$ \\
\hline Adaptação & $\begin{array}{l}\text { Apresenta um resultado se } \\
\text { adaptando com um caso já } \\
\text { existente. }\end{array}$ \\
\hline Aprendizado & $\begin{array}{l}\text { É possível armazenar um } \\
\text { caso atual para servir de } \\
\text { referência para novas } \\
\text { situações. }\end{array}$ \\
\hline
\end{tabular}

Fonte: WANGENHEIM e WANGENHEIM. (2003) Adaptado pelo Autor.

\section{ALIMENTAÇÂO}

Freitas (2002, p.15) afirma que "a alimentação influi em na disposição, no estado emocional e até na inteligência". De modo que a boa alimentação não é apenas para proporcionar uma boa aparência, mas sim para uma melhor qualidade de vida das pessoas.

Nutricionistas são profissionais que transmitem boas práticas de alimentação e que elaboram manualmente planos alimentares, baseados em seus conhecimentos, os mesmos não sendo exatos pela existência de uma infinidade de fatores que influenciam na geração do cardápio, como para distribuir de forma igualitária e ideal os grupos alimentares de acordo com as 
recomendações nutricionais para a população.

De acordo com Ornellas (2000, p. 274 -300) os seguintes fatores que influenciaram a busca de alimentos através dos tempos:

Sobrevivência: Para sobreviver foram tomadas escolhas difíceis. Os primeiros alimentos dos seres humanos foram frutos, depois vieram os tubérculos, raízes, cereais.

Outro fator que influenciou a forma de se alimentar foi o fogo. Os modos de se preparar os alimentos para consumo foram influenciados partindo dessa descoberta. Com isso, a alimentação saiu da necessidade de sobrevivência e atingiu o grau da arte.

Saúde: No início dos tempos, mesmo que o conhecimento científico fosse limitado, sabiase do poder nutricional que os alimentos possuíam. Alguns favoreciam a saúde, outros as doenças, e tal poder proporcionou 0 surgimento de bruxas e curandeiros.

Religião: A religião modela o comportamento humano. A forma que as pessoas se alimentam atualmente e em tempos antigos, são e foram influenciados pela religião. $\mathrm{O}$ ato de não comer carne sempre foi um marco para algumas religiões, como o sacrifício de animais oferecidos aos deuses nas religiões politeístas.

Ciências: $\mathrm{Em}$ paralelo com todo $\mathrm{O}$ conhecimento, grandes cientistas continuaram a aprofundar os estudos científicos que a história da humanidade possuía e alguns deles são:

Lavoisier (1743-1804): Considerado o pai da nutrição, por seus estudos sobre o consumo de oxigênio;

Liebig (1803-1853): Pesquisando a Bioquímica, chegou a composição dos alimentos;

Voit, Rubner, Atwater e Lusk: Determinaram a calorimetria humana e as leis da nutrição;

Mendel e Osborne: Determinaram a qualidade das proteínas e descobriram novas vitaminas;

Gabriel Bertand: Abre o campo para compreensão dos catalizadores minerais e exigência de elementos inorgânicos na complementação alimentar.
Esses e outros cientistas influenciaram a forma em que se compreende $o$ ato de se alimentar e de como esse ato resulta em benefícios ou malefícios à saúde.

Cultura: Pode ser considerado um conjunto de todos os outros fatores, pois é através da cultura que o povo expressa seus costumes e gostos.

De acordo Ornellas (2000), a alimentação não é um aspecto único imutável. A forma que se consome alimentos está em constante evolução, embora não existam diretrizes previamente determinadas.

Estes fatores mudam de contexto, dependendo da sociedade em que estão presentes. Por exemplo, o consumo de alguns alimentos, são considerados proibidos em algumas sociedades por aspectos políticos, sociais ou religiosos, induzindo o corpo e a mente humana a adaptar-se.

\section{SISTEMAS DE RACIOCÍNIO BASEADO EM CASOS NUTRICIONAIS}

De acordo com Minella, apud Weber (2003), o raciocínio baseado em casos $R B C$ ocorre na mentalidade humana baseando-se de acontecimentos do passado, afim de determinar uma melhor resolução para uma escolha atual. Partindo desse pressuposto, a alimentação é baseada em casos determinados por gostos vivenciados no passado.

As escolhas alimentares das pessoas estão relacionadas a um conjunto de fatores que não são tão fácies de serem alterados, uma vez que os nutricionistas encontram um desafio nesse aspecto.

Além disso, há os Softwares de nutrição que podem facilitar cálculos nutricionais relacionados com cada cardápio. O e-ExpertDiet auxiliará na elaboração e análise de planos alimentares, afim de apresentar cálculos comparativos mais eficientes. 
4.1. e-EXPERTDIET: Sistema de raciocínio baseado em Casos para análise de plano alimentar

e-ExpertDiet é um sistema baseado em caso pré-definido pelo profissional de nutrição, afim de realizar a análise dos alimentos, gerar um relatório analítico e criar uma forma de preenchimento dos alimentos no plano alimentar. É um sistema que cruza informações e consulta uma base de dados definida pelo profissional.

Ao analisar a composição
da grade alimentar, será
recomendado por meio do
sistema um determinado
alimento para completar
as necessidades
nutricionais diárias em
planos alimentares
deficientes ou a remoção
der certos alimentos
(Tabelas de substituição)
our quantidades dos
mesmos quando o plano
alimentar apresentar
superávit desnecessário
(KROTZ; PEREIRA.;
FRANCISCATTO, 2013).

Para Booch, Rumbaugh e Jacobson (2000), modelar um sistema é estritamente necessário para grandes empresas, pois através de UML (Unified Modeling Language) que os sistemas são modelados.

Na Figura 1, o diagrama de caso de uso do sistema desenvolvido retrata a interação do nutricionista com o sistema. Da mesma forma, representará a ligação do usuário com a gerência de clientes, alimentos, elaboração do cardápio baseado nos alimentos previamente cadastrados que possibilitará gerar um plano alimentar com relatórios analíticos.

Entre os casos "Montar cardápio" e "Gerenciar alimentos" foi utilizado o conceito de include e entre os casos "Montar cardápio" e "Gerar plano alimentar" e com "Gerar relatório analítico" e "Gerar plano alimentar" o conceito de extende, onde:

Include: seria a relação de um caso de uso que para ter sua funcionalidade executada precisa chamar outro caso de uso.

Extend: Esta relação significa que o caso de uso estendido vai funcionar exatamente como o caso de uso base só que alguns passos novos inseridos no caso de uso estendido. Tanto um como o outro, são notados como setas tracejadas com o texto <> ou <>. (RIBEIRO, 2017) 
Figura 1. Diagrama de caso de uso

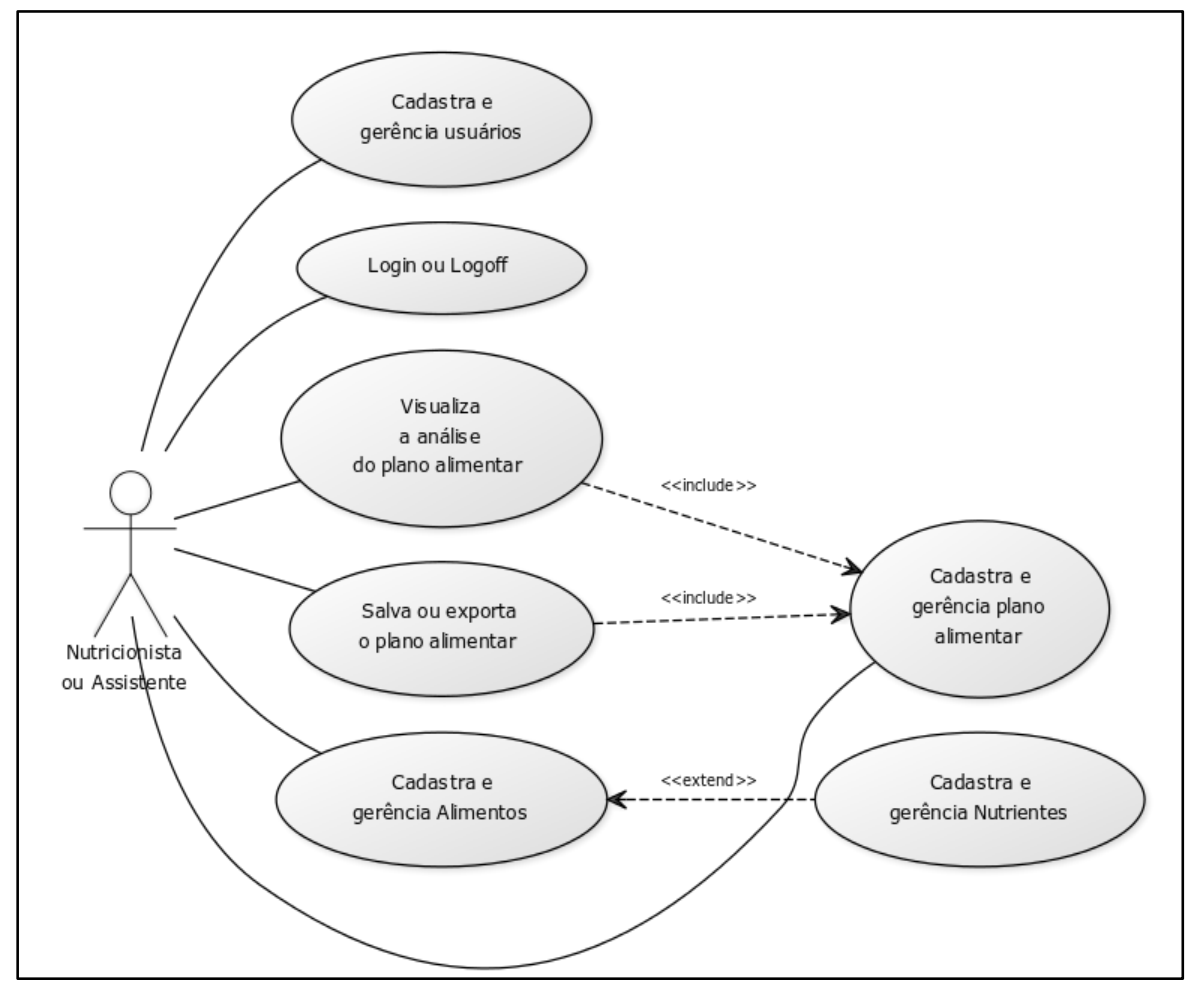

Fonte: Próprio autor.

O e-ExpertDiet possui uma interface simples, mas intuitiva. Dessa forma, o profissional de nutrição realizará o cadastro dos alimentos, nutrientes e determinará os valores recomendados para posteriormente gerar o plano alimentar e relatório analítico do cliente.

Figura 2. Interface para gerar o plano alimentar

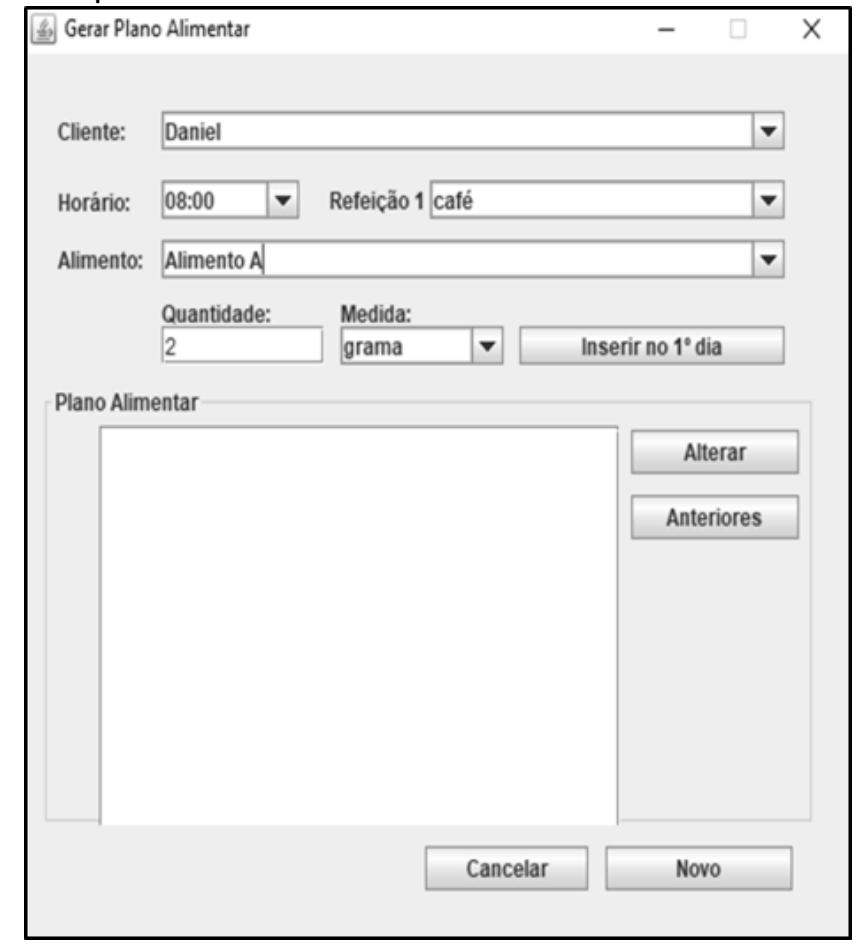


A Figura 2 demonstra a geração de um plano alimentar através da interface do eDientExpert.

O nutricionista poderá selecionar o alimento que se encontra previamente cadastrado, definindo a quantidade e a medida. Posteriormente, o profissional efetuará o clique no botão "Inserir no 10 dia". Fonte: Próprio autor.
Após o processo anterior, será preenchido automaticamente o campo do Plano Alimentar e renomeado o botão para os dias posteriores, caso houver. Ao final, possibilitará salvar o relatório em PDF contendo o plano em uma Tabela, conforme mostra a Figura 3.

Figura 3. Plano semanal

\begin{tabular}{|c|c|c|c|c|c|c|c|c|}
\hline \multicolumn{9}{|c|}{$\begin{array}{l}\text { Gerado para o cliente Daniel eleborado pela nutricionista } X \text {, na data de 23-10-2017 } \\
\text { Plano Alimentar }\end{array}$} \\
\hline \multirow{3}{*}{ 1.1. Cardápio } & & & & & & & & \\
\hline & Refeição & $\begin{array}{l}\text { Segunda- } \\
\text { feira }\end{array}$ & Terça-Feira & Quarta-Feira & Quinta-Feira & Sexta-Feira & Sabádo & Domingo \\
\hline & 08:00 - café & $\begin{array}{l}\text { Alimento A } \\
\text { na porção de } \\
2 \text { grama }\end{array}$ & Sem nada & Sem nada & Sem nada & Sem nada & Sem nada & Sem nada \\
\hline
\end{tabular}

Fonte: Próprio autor.

No exemplo acima, exposto na Figura 3 , tem o preenchimento de apenas um dia e uma refeição e também existirá a possibilidade de gerar um relatório analítico em formato PDF.
Esse relatório apresentará os alimentos que estão inseridos no cardápio, se possuem seus nutrientes nos níveis recomendados ou não, conforme demonstra a Figura 4.

Figura 4. Exportação do relatório analítico

Relatório Análitico

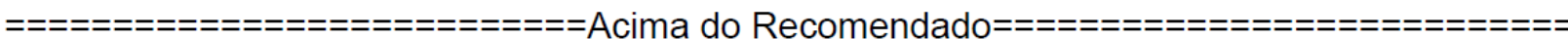

O nutriente Nutriente B possui valores superior ao recomendados, para o alimento Alimento1 da refeição 1 do dia 1 .

O nutriente Nutriente B possui valores superior ao recomendados, para o alimento Alimento1 da refeição 2 do dia 1 .

O nutriente Nutriente B possui valores superior ao recomendados, para o alimento Alimento1 da refeição 3 do dia 1 .

Fonte: Próprio autor.

Os dados para o raciocínio baseado em caso está empregado diretamente na determinação da porcentagem de cada tipo de grupo alimentar no momento da montagem do plano, tais como: verduras, legumes, frutas, leguminosas, fibras, farináceos, cereais e tubérculos, leite e derivados, frios, carnes, gorduras e óleos, oleaginosas, açucares e doces. 
Por exemplo um plano semanal para perder peso, deve ter maiores índices dos grupos de fibras e para ganhar massa muscular, maiores índices de carnes.

Ao montar o plano, será analisado se ele se adequa ao tipo de dieta escolhida no cadastro do cliente. Caso não se adeque, poderá ser cadastrado um novo tipo referência de análise de dieta, podendo ser em caráter amplo, ou mais específico, tal como, a dieta para crianças de até nove anos com deficiência de ferro.

A porcentagem de cada grupo alimentar será baseada no plano montado, apresentando comparações com outros tipos de dieta, além de permitir gerar o plano alimentar, relatório analítico, cadastrar alimentos, nutrientes, possibilitar cadastrar os clientes e apresentar um histórico de evolução de cada cliente - uma funcionalidade essencial para os profissionais de nutrição manter e visualizar a evolução de perda ou ganho de peso ou medidas de seus clientes

A interface de evolução do cliente, pode ser visualizada na Figura 5:

Figura 5. Interface do cadastro da evolução do cliente

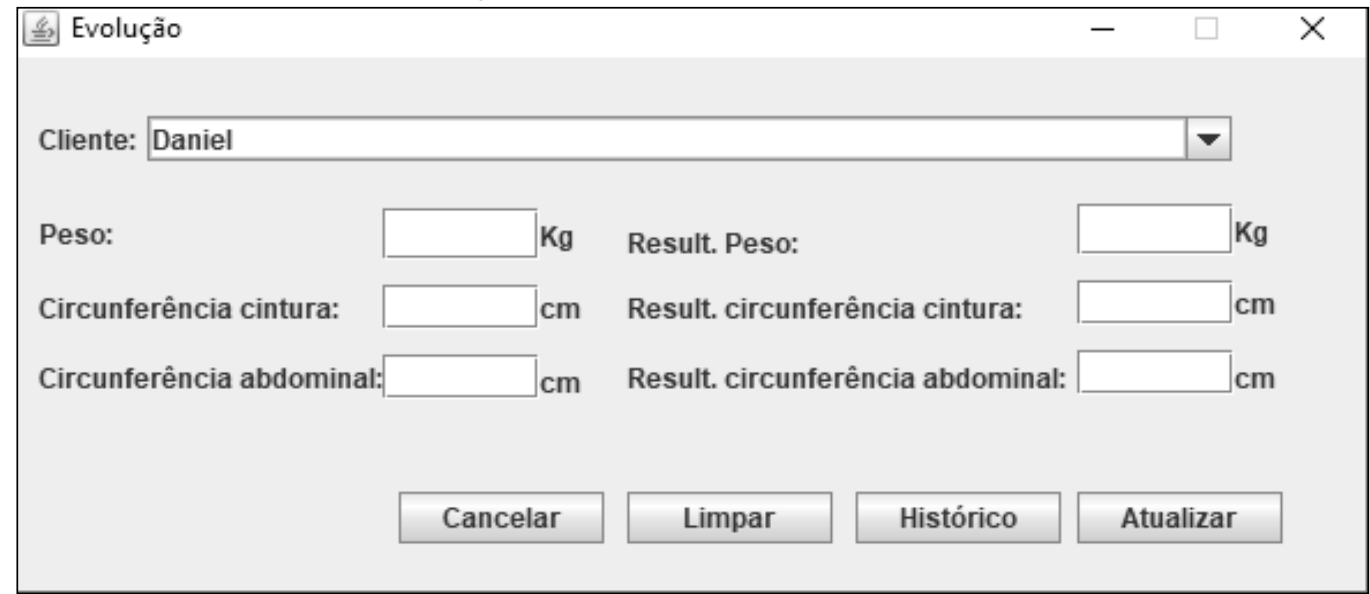

Fonte: Próprio autor.

Após preencher o nome do cliente, peso e medida e acionar o botão "Atualizar", será mostrado nos campos "Result." o resultado do ganho ou perda, baseado no respectivos valores anteriores.
Todo o histórico do cliente pode ser visualizado após efetuar um clique em "Histórico", como demonstrado na tela demonstra na Figura 6.

Figura 6. Histórico do cliente

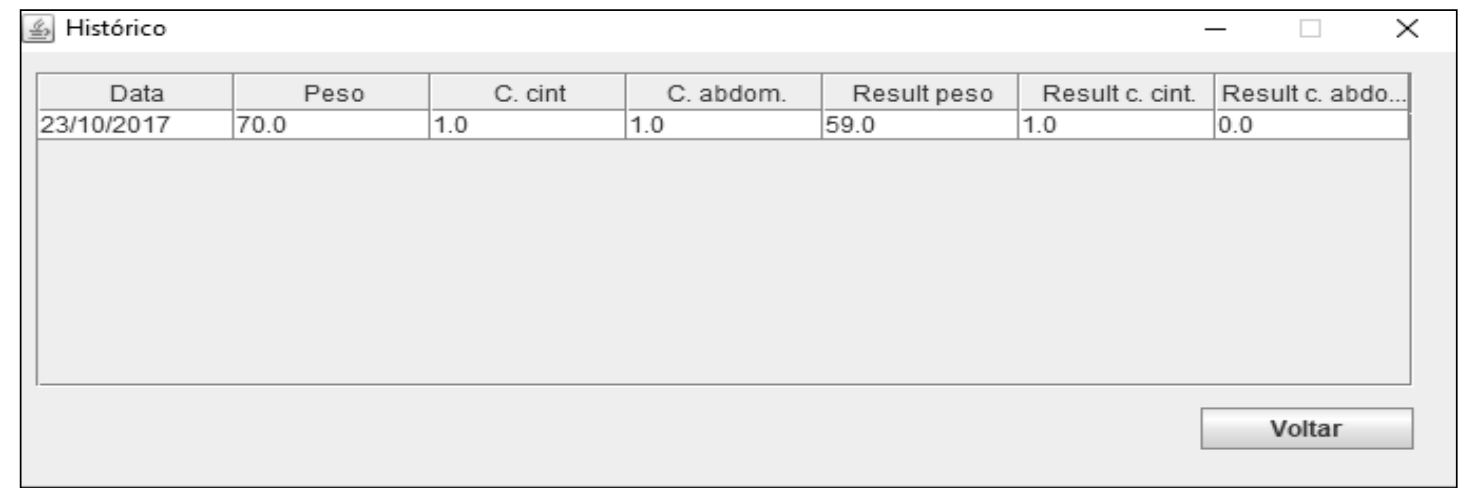

Fonte: Próprio autor. 


\section{CONSIDERAÇÕES FINAIS}

Portanto, uma boa alimentação é essencial. A economia de tempo por parte do profissional de nutrição para a elaboração da dieta balanceada é extremamente necessária.

Além do mais, há a necessidade de realizar comparações entre valores de referência e o cardápio em elaboração, para que dessa forma, sejam apontadas possíveis deficiências ou excesso que a dieta poderá ter.

Assim sendo é através da alimentação que o ser humano consegue o equilíbrio e esse é obtido com mais facilidade através dos sistemas que apoiam nutricionistas na geração desse plano.

O e-ExpertDiet é um sistema baseado em caso que quando mais sua base de referência é alimentada, mais preciso ele se tornará, chegando a um ponto, em que o plano montado pelo profissional de nutrição, seja tão específico, que consiga fornecer aos clientes dos nutricionais um equilíbrio entre a individualidade de cada cardápio com a satisfação garantida sobre o resultado final.

\section{REFERÊNCIAS}

BOOCH, G.; RUMBAUGH, J.; JACOBSON, I. UML, Guia do Usuário. tradução; Fábio Freitas da Silva. Rio de Janeiro: Campus, 2000.

DARTORA, N.; VALDUGA, A. T.; VENQUIARUTO, L. Alimentos e saúde: uma questão de educação. Vivências, Erechim., v. 1, ano 2, n. 3 p.201-212 out., 2006. Disponível em: www.reitoria.uni.br. Acesso em: 21 abr. 2014.

FERNANDES, A. M. R. Inteligência artificial: noções gerais. Florianópolis: Visual Books, , 2003.

FREITAS, P. G. Saúde um estilo de vida baseado no equilíbrio de quatro pilares. São Paulo: IBRASA, 2002.
MINELLA, C. M. S.; M. Da S, DALFOVO, O.. Raciocínio baseado em casos utilizando a dieta do tipo sanguíneo. Blumenau: FURB, [200-].

ORNELLAS, L. H. A alimentação através dos tempos. 2. ed. Florianópolis: Ed. da UFSC, 2000. 306 p.

KROTZ, J.; PEREIRA, A. S.; FRANCISCATTO, R. ANALI: Protótipo de um Sistema Especialista Web para análise de alimentos com o uso da linguagem de programação PHP. 2013. Disponível em: http://livrozilla.com/download/406832.

Acesso em: 07 set. 2017.

PAIVA, M.C. Produção de hortaliças em ambientes protegidos. 18. ed. Cuiabá,MT: Sebrae, 1998.

RIBEIRO, L.. O que é UML e diagramas de caso de uso: introdução prática à UML. Disponível em: https://www.devmedia.com.br/o-que-e-umle-diagramas-de-caso-de-uso-introducaopratica-a-uml/23408. Acesso em: 22 nov. 2017.

WANGENHEIM, C. G. von, WANGENHEIM, A. von. Raciocínio baseados em casos. Barueri, SP: Manole, 2003. 